\title{
Nettle ash as a low cost adsorbent for the removal of nickel and cadmium from wastewater
}

\author{
*H. Zavvar Mousavi; S. R. Seyedi \\ Department of Chemistry, College of Science, Universiy of Semnan, Semnan, Iran
}

Received 7 August 2010; revised 12 September 2010; accepted 20 November 2010; available online 1 December 2010

\begin{abstract}
This study was focused on nettle ash as an alternative adsorbent for the removal of nickel (II) and cadmium (II) from wastewater. Batch experiments were conducted to determine the factors affecting adsorption of nickel (II) and cadmium (II). The adsorption process is affected by various parameters such as contact time, solution $\mathrm{pH}$ and adsorbent dose. The optimum $\mathrm{pH}$ required for maximum adsorption was found to be 6 . The experimental data were tested using Langmuir, Freundlich and Tempkin equations. The data were fitted well to the Langmuir isotherm with monolayer adsorption capacity of 192.3 and $142.8 \mathrm{mg} / \mathrm{g}$ for nickel and cadmium, respectively. The adsorption kinetics were best described by the pseudo second order model. The cost of removal is expected to be quite low, as the adsorbent is cheap and easily available in large quantities. The present study showed that nettle ash was capable of removing nickel and cadmium ions from aqueous solution.
\end{abstract}

Keywords: Adsorption; Heavy metal ions; Isotherm; Kinetic; Nettle ash

\section{INTRODUCTION}

Contamination of water by toxic heavy metals through wastewater discharge by industrial activity is one of the major environmental issues. Rapid industrialization has seriously contributed to the release of toxic heavy metals in the water streams. Mining, electroplating, metal processing, textile and battery manufacturing industry are the main source of heavy metals contamination (Babel and Opiso, 2007; Nwuche and Ugoji, 2008). Those activities polluted the water streams especially rivers and made them lose their potential value and beneficial use (Kadirvelu et al., 2001; Celik and Demirbas, 2005; Demirbas et al., 2005). Heavy metals cannot be metabolized and bioaccumulate in organism body. These toxic metals can move through the biological chain thereby reaching human being and leading to chronic and acute ailments. Heavy metal toxicity can result in damage or reduced mental and central nervous function, lower energy levels and damage to blood composition, lungs, kidneys liver and organs (Volesky and Holan, 1995; Zulkali et al., 2006). Cd is a non-essential and nonbeneficial, highly toxic element to plants and animals (Kefala et al., 1999). Cd is introduced into the water

*Corresponding Author Email: hzmousavi@semnan.ac.ir Tel.: +98231 333 4802; Fax: +98231332 1005 from smelting, metal plating, cadmium-nickel batteries, phosphate fertilizers, mining, pigments, stabilizers, alloy industries and sewage sludge. Average Cd (II) concentration from plating factories is generally around $15-20 \mathrm{mg} / \mathrm{L}$, in lead mine acid drainage, the concentration can be as high as $1000 \mathrm{mg} / \mathrm{L}$. Cadmium (II) is listed as the sixth most poisonous substance jeopardizing human health. Exposure to lower amounts of cadmium may cause gastrointestinal irritation, vomiting, abdominal pain and diarrhea. Acute exposure may affect kidneys resulting in tubular proteinosis and sometimes fatality (Prasad et al., 2006) The most common adverse health effect of nickel in humans is an allergic reaction; large amounts of nickel can cause lung and nasal sinus cancers. Nickel is also toxic, especially to activated sludge bacteria. The presence of $\mathrm{Ni}$ (II) is detrimental to the operation of anaerobic digesters used in wastewater treatment plants. Cd (II) and Ni (II) ions are frequently encountered together in industrial wastewaters. Hence, it is essential to removal Cd and $\mathrm{Ni}$ from industrial wastewaters before transport and cycling into the nature environment. Removal of heavy metals from wastewater is usually achieved by physical and chemical processes which include precipitation, coagulation reduction membrane procession change 
(Gode and Pehlivan, 2006) and adsorption (Krishnani et al., 2008; Abdel-Ghani et al., 2009; Shah et al., 2009). All the chemical methods have proved to be much expensive and less efficient than the adsorption process. In addition, chemical methods increase the pollution load on the environment. Adsorption has advantages over the other methods because of simple design with a sludge free environment and can involve low investment in term of both initial cost and land required. Several materials derived from natural resources, plant wastes or industrial by-products such as peat, wood, barley, rice husk, plant straw, rice bran, peanut straw, almond straw hazelnut straw, algal biomass, banana pith, soybean, cottonseed hulls, humic acids, tree bark, sugar beet pulp, leaves, green algae, activated carbon fibers, coconut waste, wood and straw have all been investigated for their ability to sequester trace metals from water. In recent years, numerous lowcost natural materials such as palm shell (Igwe et al., 2008; Onundi et al., 2010), hazelnut shell (Cimino et al., 2000), potato peels (Aman et al., 2008), sewage sludge ash (Pan et al., 2003), sawdust (Yu et al, 2001), leca (Malakootian et al., 2009), tea waste (Amir et al., 2005), wood ash (Malakootian et al., 2008), red mud (Apak et al., 1998), husk (Babarinde, 2002), maize tassel (Zvinowanda et al., 2009), and other adsorbents (AlRub, 2006; Radhika et al., 2006; Aydýn et al., 2008; Mahvi, 2008; Qi and Aldrich, 2008) were used and investigated for removal of heavy metals from water and wastewaters. In the present work, a cheap, readily available and effective adsorbent material has identified nettle ash as a potentially attractive adsorbent for the treatment of $\mathrm{Ni}$ (II) and Cd (II) contaminated aqueous solutions. The effects of adsorbent concentration, $\mathrm{pH}$, contact time and initial metal ion concentration on the adsorption capacity were investigated. The rate kinetics and equilibrium parameters were determined. Adsorption isotherm models and thermodynamic parameters were also investigated. This research was performed in Semnan University of Iran from January until September 2009 in Semnan.

\section{MATERIALS AND METHODS}

\section{Materials}

All reagents used were of analytical (Merck) grade. Test solutions of binary metal ions were prepared from their nitrate salts by serial dilution of stock cadmium and nickel ion solution $(1000 \mathrm{mg} / \mathrm{L})$ using deionized distilled water. Blank solution of deionized distilled water was analyzed by AAS to ensure that it did not contain cadmium and nickel ions. Before mixing these solutions with the adsorbent, $\mathrm{pH}$ values of them were adjusted by adding $0.1 \mathrm{~mol} / \mathrm{L} \mathrm{NaOH}$ and $0.1 \mathrm{~mol} / \mathrm{L} \mathrm{HNO}_{3}$. E-632 pH meter (Metrohm) was used to measure the $\mathrm{pH}$ values of the solutions.

\section{Adsorbent preparation}

In this study, nettle ash was used as an adsorbent for the removal of heavy metals. Nettle is found mostly in northern cities of Iran. This plant is bothersome for farmers and stop process of growth or development of plants, so it should be emitted from this area. To prepare the adsorbent, a certain amount of nettle plants were collected and washed with distilled water. After that the burned dried plant materials was placed into a porcelain crucible at $500^{\circ} \mathrm{C}$ in a muffle furnace for $4 \mathrm{~h}$.

\section{Batch adsorption studies}

Batch experiments were carried out at various $\mathrm{pH}$ (2-7), adsorbent dose (1-5 g/L) and stirring speed (180 rpm) for a contact time of $60 \mathrm{~min}$. For each batch experiment, $100 \mathrm{~mL}$ of $100 \mathrm{mg} / \mathrm{L}$ both metal ions solution was used. After setting $\mathrm{pH}$ and adding desired amount of adsorbent the mixture was agitated on mechanical shaker for $60 \mathrm{~min}$. After that the mixture was filtered to separate the adsorbent from supernatant. The residual concentration of both ions was determined by flame atomic spectrometer. All experiments were replicated thrice for all the adsorbents and results were averaged. The removal percentage $(R$ $\%)$ of nickel and cadmium were calculated for each run by the following expression:

$\mathrm{R} \%=\frac{\left(C_{i}-C_{e}\right)}{C_{i}} \times 100$

where $\mathrm{C}_{\mathrm{i}}$ and $\mathrm{C}_{\mathrm{e}}$ are the initial and final concentration of both ions in the solution. The adsorption capacity of an adsorbent which is obtained from the mass balance on the sorbate in a system with solution volume $\mathrm{V}$ is often used to acquire the experimental adsorption isotherms. Under the experimental conditions, the adsorption capacities of all the adsorbents for each concentration of $\mathrm{Ni}^{2+}$ and $\mathrm{Cd}^{2+}$ ions at equilibrium were calculated using Eq. (2).

$\mathrm{q}_{\mathrm{e}}(\mathrm{mg} / \mathrm{g}) \%=M \frac{\left(C_{i}-C_{e}\right)}{M} \times V$ 
where $\mathrm{C}_{i}$ and $\mathrm{C}_{\mathrm{e}}$ are the initial and final concentration of both ions in the solution respectively. $\mathrm{V}$ is the volume of solution (L) and $\mathrm{M}$ is the mass of adsorbent (in g.) used.

\section{Analytical techniques}

Atomic absorption spectrophotometry with an airacetylene flame and hollow cathode lamps for $\mathrm{Cd}$ and $\mathrm{Ni}$ was used for metal ions analysis. A Phillips XL30 electron microscope was used to take view of the adsorbent.

\section{RESULTSAND DISCUSSION}

\section{Adsorbent characterization}

A scanning electron microscope (SEM) was used to examine the surface of the nettle ash. The SEM image (Fig. 1) shows a highly porous morphology of adsorbent with pores of different sizes and shapes.

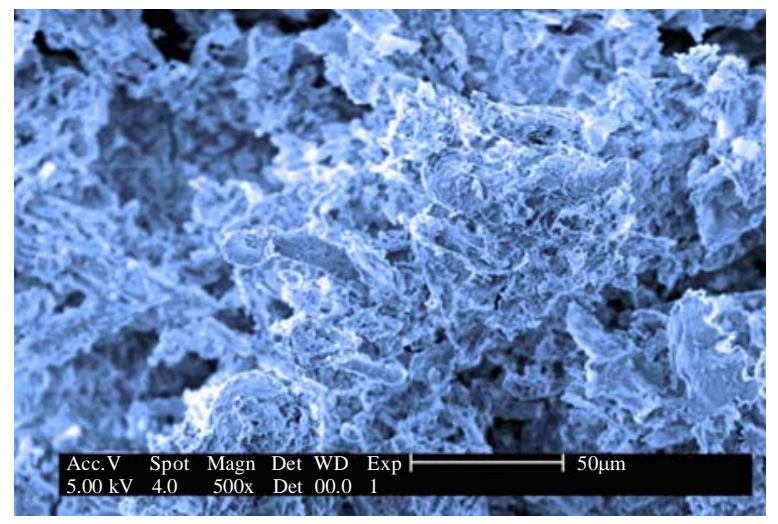

Fig. 1: Scanning electron micrographs of the NA

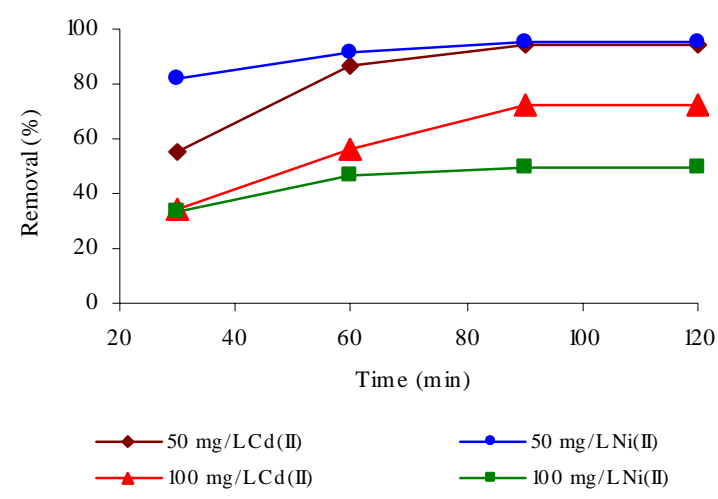

Fig. 2: Effect of contact time on the binary adsorption of nickel and cadmium ions (stirring speed: $180 \mathrm{rpm}$; amount of sorbent: $0.5 \mathrm{~g} / \mathrm{L}$, temperature: $25^{\circ} \mathrm{C}$ ).

\section{Effect of contact time}

The removal of $\mathrm{Ni}^{2+}$ and $\mathrm{Cd}^{2+}$ from binary solution as a function of time is presented in Fig. 2. It can be seen that the adsorbed amount of both metal ions increased by increasing contact time and reached equilibrium after $60 \mathrm{~min}$. Therefore; $60 \mathrm{~min}$ was selected as the contact time for both metal ions in the single and binary solutions.

\section{Effect of adsorbent dose}

The adsorbent dose is an important parameter in adsorption studies because it determines the capacity of adsorbent for a given initial concentration of metal ion solution. The effect of adsorbent dose on the percent removal of $\mathrm{Ni}$ (II) and Cd (II) at initial concentration of $100 \mathrm{mg} / \mathrm{L}$ is shown in Fig. 3. From the figure it can be observed that increasing of adsorbent dose increased the percent removal of Ni(II) and Cd (II) up to $97.1 \%$ and $86.2 \%$, respectively, with the required optimum dosage of $0.5 \mathrm{~g} / \mathrm{L}$. (Fig. 3). Beyond the optimum dosage the removal efficiency did not change with the adsorbent dose. As expected, the removal efficiency increased with increasing the adsorbent dose for a given initial metal concentration, because for a fixed initial adsorbate concentration increasing adsorbent dose provides greater surface area or more adsorption sites. (Kumar et al., 2006; Jayaram, et al., 2009)

\section{Effect of initial metal ion concentration}

The heavy metal ions adsorption by NA is given as a function of initial concentration of heavy metal ions within the aqueous phase in Fig. 4a, Fig. 4b. These

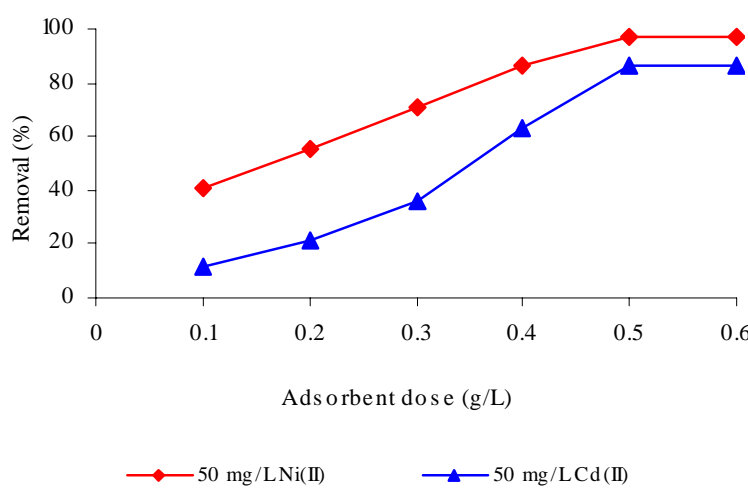

Fig. 3: Effect of adsorbent dose on the adsorption of Ni (II) and Cd (II) ions (Stirring speed: $180 \mathrm{rpm}$; heavy metal concentration $100 \mathrm{~mL}$ of $50 \mathrm{mg} / \mathrm{L}$, temperature: $25^{\circ} \mathrm{C}$ ) 

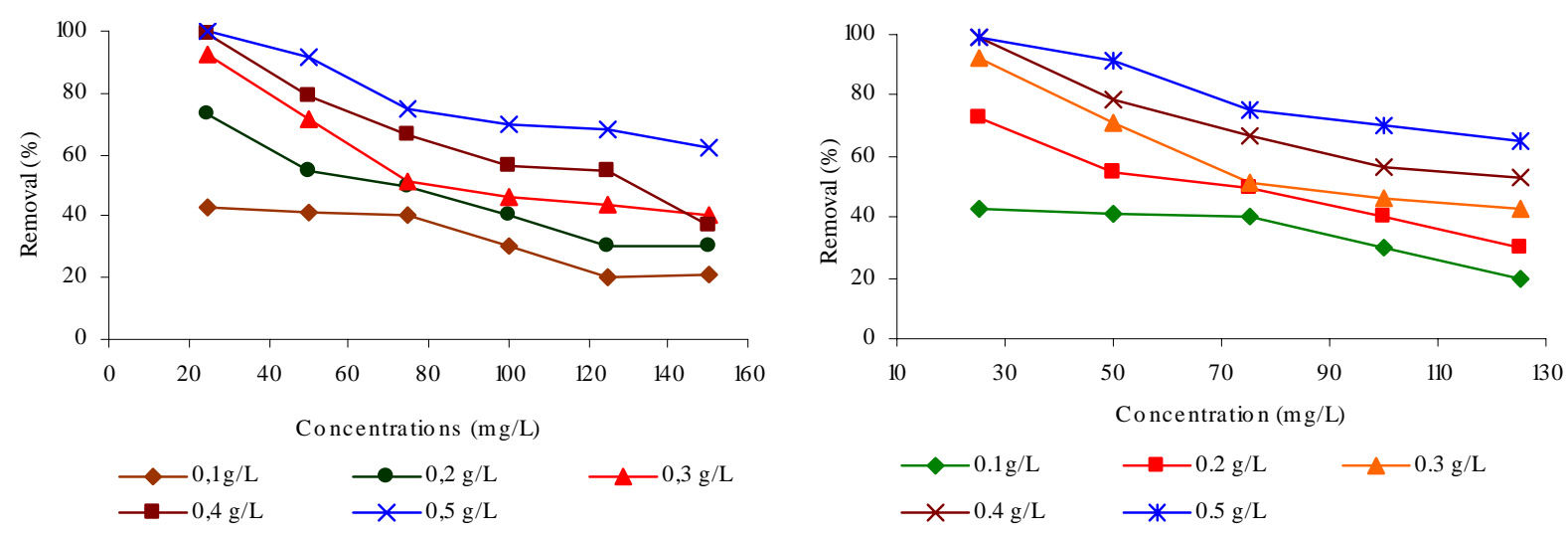

Fig. 4 :Effect of initial concentration on the adsorption of heavy metals onto adsorbent, (a) Ni (II), (b) Cd (II)

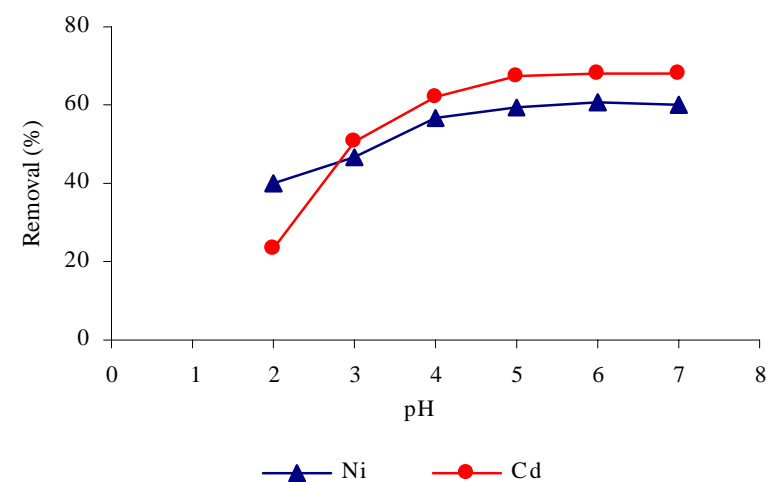

Fig. 5: Effect of system $\mathrm{pH}$ on adsorption of $\mathrm{Ni}(\mathrm{II})$ and $\mathrm{Cd}(\mathrm{II})$ onto NA (Stirring speed: 180 rpm; heavy metal concentration $50 \mathrm{mg} / \mathrm{L}$, NA $0.5 \mathrm{~g} / \mathrm{L}$, temperature: $\left.25^{\circ} \mathrm{C}\right)$.

adsorption curves were obtained from experiments where adsorptions from the binary heavy metal aqueous solutions were studied. From this figure, it can be observed that the ion removal percentage increases when the initial ion concentration decreases. At low ion concentrations the ratio of surface active sites to the total metal ions in the solution is high and hence all metal ions may interact with the adsorbent and be removed from the solution (Chen et al., 2005).

\section{Effect of $p H$}

Earlier studies on heavy metals adsorption have shown that $\mathrm{pH}$ is the most important parameter affecting the adsorption process. Aqueous phase $\mathrm{pH}$ governs the speciation of metals and also the dissociation of active functional sites on the sorbent. Hence, metal sorption is critically linked with $\mathrm{pH}$. To find the optimum $\mathrm{pH}$ for the effective adsorption of nickel and cadmium ions by nettle ash, experiments were performed at different initial $\mathrm{pH}$ values (2-7). The variation of $\mathrm{Ni}$ (II) and Cd (II) removal with initial $\mathrm{pH}$ is given in Fig. 5. When the nettle ash was hydrated, its $\mathrm{pH}$ reached $10-13$, where a high degree of the precipitation of metal ions can be expected. The percent removal of the heavy metal ions increased as the $\mathrm{pH}$ increased. This phenomenon can be explained by the surface charge of the adsorbent and the $\mathrm{H}^{+}$ions present in the solution. At low $\mathrm{pH}$ the cations compete with the $\mathrm{H}^{+}$ions in the solution for the active sites and therefore lower adsorption. The surface charge of the adsorbent is a strong function of the $\mathrm{pH}$. Therefore at high $\mathrm{pH}$ values surface of the adsorbent has a higher negative charge which results higher attraction of cations. Hence adsorption of Cd (II) and Ni (II) cations onto nettle ash is at optimum in the $\mathrm{pH}$ 6. At a higher $\mathrm{pH}$, the both ions precipitated as their hydroxides which decreased the rate of adsorption and subsequently the percent removal of metal ions (Pagnanelli et al., 2003; LugoLugo et al., 2009).

\section{Adsorption isotherms}

Several equilibrium models have been developed to describe adsorption isotherm relationships. The adsorption of cadmium and nickel ions was carried out at different initial Cd(II) and Ni(II) ions concentrations ranging from 25 to $150 \mathrm{mg} / \mathrm{L}$, at $100 \mathrm{rpm}$ with the optimum agitation period. The data obtained were analyzed with theLangmuir, Freundlich and Tempkin, isotherm equations. The best-fitting isotherm was tested by determination of the linear regression, and the parameters of the isotherms have been obtained from the intercept and slope of the linear plots of the different isotherm models. 

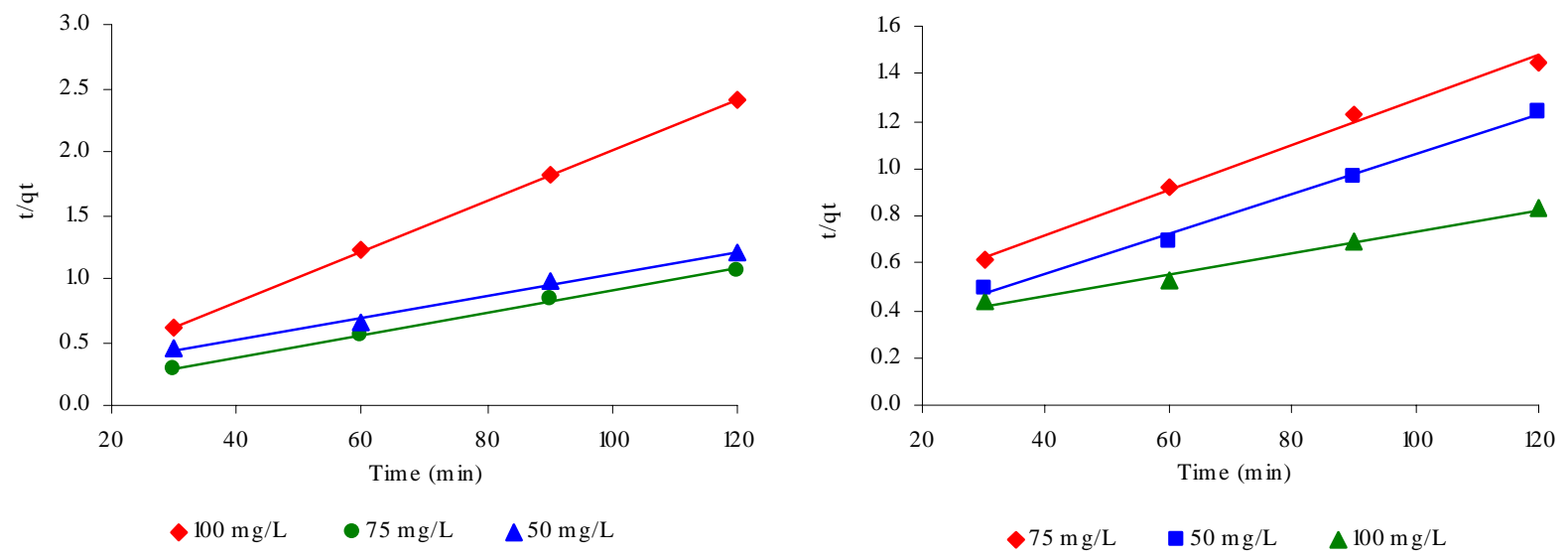

Fig. 6: Pseudo-second order kinetics of (a) Ni (II) ,(b) Cd (II) onto nettle ash: 0.05 g of nettle ash mixed with $100 \mathrm{~mL}$ solution, $22{ }^{\circ} \mathrm{C}$.

\section{Langmuir isotherm}

One of widespread-used models for describing heavy metals sorption to adsorbents is the Langmuir model. Langmuir equation relates the coverage of molecules on a solid surface to concentration of a medium above the solid surface at a fixed temperature. In addition, the model assumes uniform energies of adsorption onto the surface and no transmigration of the adsorbate (Langmuir, 1916). Estimation of maximum adsorption capacity corresponding to complete monolayer coverage on the nettle ash was calculated using the Langmuir isotherm model since the saturated monolayer isotherm can be explained by the non-linear equation of Langmuir Eq. (3).

$$
\frac{c_{e}}{q_{e}}=\frac{1}{b Q_{m}}+\frac{c_{e}}{Q_{m}}
$$

where $\mathrm{C}_{\mathrm{e}}$ is the equilibrium concentration $(\mathrm{mg} / \mathrm{L}), \mathrm{q}_{\mathrm{e}}$ the amount of metal ion adsorbed $(\mathrm{mg} / \mathrm{g}), \mathrm{Q}_{\mathrm{m}} \mathrm{a}$ completemonolayer $(\mathrm{mg} / \mathrm{g})$ and $\mathrm{b}$ is a parameter related to the energy of adsorption, respectively (Lalhruaitluanga et al., 2010).

\section{The Freundlich isotherm}

Freundlich isotherm is an empirical equation. This equation is one among the most widely used isotherms for the description of adsorption equilibrium. Freundlich isotherm is capable of describing the adsorption of organic and inorganic compounds on a wide variety of adsorbents. The Freundlich equation is expressed (Kalavathy et al., 2005).

$\mathrm{Q}_{\mathrm{e}}=\mathrm{K}_{\mathrm{F}} \mathrm{C}_{\mathrm{e}}^{1 / \mathrm{n}}$
The linear form of the equation can be written as:

$\operatorname{Ln} \mathrm{Qe}=\ln \mathrm{K}_{\mathrm{F}}+1 / \mathrm{n} \ln \mathrm{C}_{\mathrm{e}}$

Where $\mathrm{K}_{\mathrm{F}}$ and $\mathrm{n}$ are the Freundlich constants related to the adsorption capacity and adsorption intensity, respectively. The intercept and the slope of the linear plot of $\ln$ Qe versus ln Ce at given experimental conditions provide the values of $K_{F}$ and $1 / n$, respectively.

\section{The Tempkin isotherm}

Tempkin isotherm plot was chosen to evaluate adsorption potentials of sorbent for sorbate. The heat of sorption of the molecules in layer decreases linearly with coverage due to sorbate and sorbent interactions. Tempkin isotherm assumes that the fall in the heat of sorption is linear rather than logarithmic. Tempkin isotherm model is shown:

$q_{e}=\frac{R T}{b_{T}} \ln K_{T}+\frac{R T}{b_{T}} \ln C_{e}$

where $K_{\mathrm{T}}\left(\mathrm{dm}^{3} / \mathrm{g}\right)$ is Tempkin adsorption potential and $b_{\mathrm{T}}(\mathrm{kJ} / \mathrm{mol})$ is heat of sorption (Table 1$)$. When evaluated with respect to coefficient of determination $\left(R^{2}=0.82\right.$, Tempkin isotherm model appears not to be favorable for fitness to the experimental data (Nadeem, et al., 2009). The value of Langmuir and Freundlich isotherm model constants are shown in Table 1. Examination of the correlation coefficients reported in study shows that Langmuir isotherm model was found to be applicable in interpreting $\mathrm{Ni}(\mathrm{II})$ and $\mathrm{Cd}(\mathrm{II})$ adsorption by NA. The maximum monolayer capacity, 
H. Zavvar Mousavi; S. R. Seyedi

Table 1: The langmuir and freundlich isotherm model constants

\begin{tabular}{lcccccc}
\hline Ion & \multicolumn{3}{c}{ Freundlich } & \multicolumn{3}{c}{ Langmuir } \\
\cline { 2 - 7 } & $1 / \mathrm{n}$ & $\mathrm{K}_{\mathrm{F}}$ & $\mathrm{R}^{2}$ & $\mathrm{Q}_{\mathrm{m}}$ & $\mathrm{K}_{\mathrm{L}}$ & $\mathrm{R}^{2}$ \\
$\mathrm{Ni}(\mathrm{II})$ & 0.16 & 83.9 & 0.920 & 192.3 & 0.16 & 0.973 \\
$\mathrm{Cd}(\mathrm{II})$ & 0.187 & 55.94 & 0.910 & 142.8 & 0.13 & 0.960 \\
\hline
\end{tabular}

Table 2: Second order kinetic parameters for adsorption of $\mathrm{Ni}(\mathrm{II})$ and $\mathrm{Cd}(\mathrm{II})$ onto NA

\begin{tabular}{cccc}
\hline Metal & Initial solution concentration $(\mathrm{mg} / \mathrm{L})$ & $\mathrm{R}^{2}$ & $\mathrm{~K}_{2}(\mathrm{~g} / \mathrm{mg} / \mathrm{min})$ \\
\hline & 25 & 0.999 & 0.027 \\
$\mathrm{Ni}(\mathrm{II})$ & 75 & 0.999 & $7.26 \times 10^{-3}$ \\
& 100 & 0.9926 & $4.38 \times 10^{-4}$ \\
$\mathrm{Cd}(\mathrm{II})$ & 25 & 0.999 & 0.036 \\
& 75 & 0.9973 & $5.32 \times 10^{-5}$ \\
& 100 & 0.9903 & $7.13 \times 10^{-5}$ \\
\hline
\end{tabular}

Table 3: Comparison of adsorption capacity of various adsorbent for $\mathrm{Ni(II)}$ and $\mathrm{Cd}(\mathrm{II})$

\begin{tabular}{lccl}
\hline Adsorbent & \multicolumn{2}{c}{ Adsorbent capacity (mg/g) } & \\
\hline & $\mathrm{Ni}(\mathrm{II})$ & $\mathrm{Cd}(\mathrm{II})$ & \multicolumn{1}{c}{ Reference } \\
Ilgın lignite & 13.0 & ---- & (Pehlivan and Arslan. 2007) \\
Zeolite & 8.96 & ---- & (Hui et al.2005) \\
Lentinus edodes pellets & ---- & 78.6 & (Bayramoglu and Arica. 2008) \\
Activated pine bark & & 30.21 & (Argun and Dursun. 2008) \\
black gram husk & 19.56 & 39.99 & (Saeed et al. 2005) \\
Nettle ash & 192.3 & 142.8 & This study \\
\hline
\end{tabular}

$\mathrm{Q}_{\mathrm{m}}$, obtained from the Langmuir isotherm were 192.3 and $142.8 \mathrm{mg} / \mathrm{g}$ for nickel and cadmium, respectively.

\section{Adsorption kinetics}

In order to investigate the controlling mechanism of adsorption processes such as mass transfer and chemical reaction, the pseudo-first-order and pseudosecond-order equations are applied to model the kinetics of metal ions adsorption onto NA.

\section{Pseudo-first-order model}

Lagergren proposed a pseudo-first-order kinetic model. The integral form of the model is

$$
\log \left(\mathrm{q}_{\mathrm{e}}-\mathrm{q}_{\mathrm{t}}\right)=\log \mathrm{q}_{\mathrm{e}}-\frac{K_{a d}}{2.303} \mathrm{t}
$$

where $q$ is the amount of both ions sorbed (mg/g) at time $t$ (min), $q_{\mathrm{e}}$ is the amount of metal ions sorbed at equilibrium $(\mathrm{mg} / \mathrm{g})$, and $K_{\text {ad }}$ is the equilibrium rate constant of pseudo-first-order adsorption (1/min). This model was successfully applied to describe the kinetics of many adsorption systems (Weng and Huang, 2004).

\section{Pseudo-second-order model}

The adsorption kinetics may also be described by a pseudo second-order reaction. The linearized integral form of the model is:

$$
\frac{t}{q_{t}}=\frac{1}{k_{2} q_{e}^{2}}+\frac{t}{q_{e}}
$$

where $K_{2}$ is the pseudo-second-order rate constant of adsorption (Mc Kay and Ho, 1999). The applicability of the above two models can be examined by each linear plot of $\log \left(q_{\mathrm{e}}\right.$ “ $\left.q\right)$ versus $t$, and $(t / q)$ versus $t$, respectively and are presented in Figs. 6 (a) and 6 (b). To quantify the applicability of each model, the correlation coefficient, $R^{2}$, was calculated from these plots. The linearity of these plots indicates the applicability of the two models. However, the correlation coefficients, $R^{2}$, showed that the pseudo-second-order model, an indication of a chemisorptions mechanism, fits better the experimental data ( $\left.R^{2}>0.99\right)$ than the pseudo-first-order model (Table2).

Comparison of metal ions removal with different adsorbents reported in literature

The adsorption capacities of the adsorbents for the removal of both ions have been compared with those of 
other adsorbents reported in literature and the values of adsorption capacities have been presented in Table 3. The values are reported in the form of monolayer adsorption capacity. The experimental data of the present investigations are higher than other reported values in some cases. The adsorption capacity varies and it depends on the characteristics of the individual adsorbent, the extent of surface/surface modification and the initial concentration of the adsorbate. However, the present experiments are conducted to find the technical applicability of the lowcost adsorbents to treat Ni (II) and Cd (II).

\section{CONCLUSION}

The aim of this work was investigating removal of $\mathrm{Ni}$ (II) and Cd (II) from aqueous solutions by using nettle ash. Optimal removal conditions for both metals were determined with batch experiments. The equilibrium time for adsorption of metal ions from aqueous solutions was achieved within 60 min of contact time. The $\mathrm{pH}$ experiments showed that showed that maximum adsorption occurred at $\mathrm{pH} 6$ for the two studied metal ions. The Langmuir adsorption isotherm model was better used to represent the experimental data. The monolayer adsorption capacity was obtained 192.3 and $142.8 \mathrm{mg} / \mathrm{g}$ for Ni (II) and Cd (II), respectively. The adsorption kinetics fit to pseudo second order model. The experimental data of the present investigations are comparable with the reported values in some cases. It is important to remark that nettle ash is very cheap and highly available material and after treatment, the created sludge could be buried in an appropriate landfill. We note that our material is more effective compared to other adsorbents. The results obtained in this study; show that nettle ash is a good and effective adsorbent for the removal of heavy metals and could be used in water and wastewater treatment.

\section{ACKNOWLEDGEMENT}

The authors are grateful for the financial support provided by Semnan University Scientific Research Foundation (Project No.266/87/6535).

\section{REFERENCES}

Abdel-Ghani, N. T.; Hegazy, A. K.; El-Chaghaby, G. A., (2009). Typha domingensis leaf powder for decontamination of aluminium, iron, zinc and lead: Biosorption kinetics and equilibrium modeling. Int. J. Environ. Sci. Tech. 6 (2), 243248 (6pages).

Al-Rub, F. A. A., (2006). Biosorption of Zinc on Palm Tree Leaves: Equilibrium, Kinetics, and Thermodynamics Studies. Sep. Sci. Tech., 41 (15), 3499-3515 (17 pages).

Aman, T.; Kazi, A. A.; Sabri, M. U.; Bano, Q., (2008).Potato peels as solid waste for the removal of heavy metal copper
(II) from waste water/industrial effluent. Colloid. Surface. B., 63 (1), 116-121 (6 pages).

Amir, H. M.; Dariush, N.; Forugh, V.; Shahrokh, N., (2005). Tea waste as and Adsorbent for Heavy Metal Removal from Industrial Wastewaters. Am. J. Appl. Sci., 2 (1), 372-375 (4 pages).

Apak, R.; Tutean, E.; Hugul, M.; Hizal, J., (1998). Heavy metal cation retention by unconventional sorbents (red muds and fly ashes).Water Res., 32 (2), 430-440 (11 pages).

Argun, M. E.; Dursun, S., (2008). Cadmium removal using activated pine bark. J. Int. Environ. Appl. Sci. 3 (1), 37-42 (6 pages).

Aydýn, H.; Bulut, Y.; Yerlikaya, C., (2008). Removal of copper (II) from aqueous solution by adsorption onto low-cost adsorbents. J. Environ. Manage., 87 (1), 37-45 (9 pages).

Babarinde, N. A. A., (2002). Adsorption of zinc (II) and cadmium (II) by. Coconut husk and goat Hair. J. Pure Appl. Sci., 5, 8185 (5 pages).

Babel, S.; Opiso, E. M., (2007). Removal of Cr from synthetic wastewater by sorption into volcanic ash soil. Int. J. Environ. Sci. Tech. 4 (1), 99-108 (10pages).

Bayramoglu, G.; Arýca, M. Y., (2008). Removal of heavy mercury (II), cadmium (II) and zinc (II) metal ions by live and heat inactivated Lentinus edodes pellets. Chem. Eng. J. 143 (1-3), 133- 140 (8 pages).

Celik, A.; Demirbas, A., (2005). Removal of heavy metal ions from aqueous solutions via adsorption onto modified lignin from pulping wastes. Energy Sour., 27, 1167-1177 (11 pages).

Cimino, G.; Passerini, A.; Toscano, G., (2000). Removal of toxic cations and $\operatorname{Cr}(\mathrm{VI})$ from aqueous solution by hazelnut shell. Water. Res., 34 (11), 2955-2962 (8 pages).

Chen, X. C.; Wang, Y. P.; Lin, Q.; Shi, J. Y.; Wu, W. X.; Chen, Y. X., (2005). Biosorption of copper(II) and zinc (II) from aqueous solution by Pseudomonas putida CZ1, Colloid. Surf. B., 46 (2), 101-107 (7 pages).

Demirbas, A.; Pehlivan, E.; Gode, F.; Altun, T.; Arslan, G., (2005). Adsorption of $\mathrm{Cu}(\mathrm{II}), \mathrm{Zn}$ (II), Ni (II), Pb (II), and Cd (II) from aqueous solution on Amberlite IR-120 synthetic resin. J. Colloid Interface Sci. Surf., 282 (1), 20-25 (6 pages).

Gode, F.; Pehlivan, E., (2006). Removal of chromium(III) from aqueous solutions using Lewatit S 100: The effect of $\mathrm{pH}$, time, metal concentration and temperature. J. Hazard. Mater., 136 (2), 330-337 (8 pages).

Hui, K. S.; Chao, C. Y. H.; Kot, S. C., (2005). Removal of mixed heavy metal ions in wastewater by zeolite $4 \mathrm{~A}$ and residual products from recycled coal fly ash. J. Hazard. Mater., 127 (1-3), 89-101 (13 pages).

Igwe, J. C.; Abia, A. A.; Ibeh, C. A., (2008). Adsorption kinetics and intraparticulate diffusivities of $\mathrm{Hg}$, $\mathrm{As}$ and $\mathrm{Pb}$ ions on unmodified and thiolated coconut fiber. Int. J. Environ. Sci. Tech., 5 (1), 83-92 (10pages).

Jayaram, K.; Murthy, I. Y. L. N.; Lalhruaitluanga, H.; Prasad, M. N. V., (2009). Biosorption of lead from aqueous solution by seed powder of Strychnos potatorum L. Colloid Surf. B., 71 (2), 248-254 (7 pages).

Kadirvelu, K.; Thamaraiselvi, K.; Namasivayam, C.,(2001). Removal of heavy metals from industrial wastewaters by adsorption onto activated carbon prepared from an agricultural solid waste. Bioresour. Tech., 76 (1), 63-65 (3 pages).

Kalavathy, M. H.; Karthikeyan, T.; Rajgopal, S.; Miranda, L. R., (2005). Kinetic and isotherm studies of $\mathrm{Cu}$ (II) adsorption 
onto $\mathrm{H}_{3} \mathrm{PO}_{4}$-activated rubber wood sawdust. J. Colloid Interface Sci., 292 (2), 354-362 (9 pages).

Kefala, M. I.; Zouboulis, A. I.; Matis, K. I., (1999). Biosorption of cadmium ions by Actinomycetes and separation by flotation. Environ. Pollut., 104 (2), 283-293 (11 pages).

Krishnani, K. K.; Meng, X.; Christodoulatos, C.; Boddu, V. M., (2008). Biosorption mechanism of nine different heavy metals onto biomatrix from rice husk. J. Hazard. Mater., 153 (3), 1222-1234 (13 pages).

Kumar, Y. P.; King, P.; Prasad, V. S. R. K., (2006). Equilibrium and kinetic studies for the biosorption system of copper(II) ion from aqueous solution using Tectona grandis L.f. leaves powder. J. Hazard. Mater., 137 (2), 1211- 1217 (7 pages).

Lalhruaitluanga, H.; Jayaram, K.; Prasad, M. N. V.; Kumar, K. K., (2010). Lead (II) adsorption from aqueous solutions by raw and activated charcoals of Melocanna baccifera Roxburgh (bamboo) A comparative study. J. Hazard. Mater., 175 (1-3), 311-318 (8 pages).

Langmuir, I., (1916). The constitution and fundamental properties of solids and liquids, J. Am. Chem. Soc., 38, $2221-$ 2295 (75 pages).

Lugo-Lugo, V.; Hernandez-Lopez, S.; Barrera-Diaz, C., (2009). A comparative study of natural, formaldehyde-treated and copolymer-grafted orange peel for $\mathrm{Pb}$ (II) adsorption under batch and continuous mode. J. Hazard. Mater., 161 (2-3), 1255-1264 (10 pages).

Mahvi, A. H., (2008). Application of agricutural fibers in pollution removal from aqueous solution. Int. J. Environ. Sci. Tech., 5 (2), 275-285 (11 pages).

Malakootian, M.; Almasi, A.; Hossaini, H., (2008). Pb and Co removal from paint industries effluent using wood ash. Int. J. Environ. Sci. Tech., 5 (2), 217-222 (6 pages).

Malakootian, M.; Nouri, J.; Hossaini, H., (2009). Removal of heavy metals from paint industry's wastewater using Leca as an available adsorbent. Int. J. Environ. Sci. Tech., 6 (2), 183190 (8 pages).

Mc Kay, G.; Ho, Y. S., (1999). Pseudo-second order model for sorption processes. Process Biochem., 34 (5), 451-465 (15 pages).

Nadeem, R.; Nasir, M. H.; Hanif, M. S., (2009). Pb (II) sorption by acidically modified Cicer arientinum biomass. Chem. Eng. J., 150 (1), 40-48 (9 pages).

Nwuche, C. O.; Ugoji, E. O., (2008). Effects of heavy metal pollution on the soil microbial activity. Int. J. Environ. Sci. Tech., 5 (3), 409-414 (6 pages).

Onundi, Y. B.; Mamun, A. A.; Al Khatib, M. F.; Ahmed, Y. M., (2010). Adsorption of copper, nickel and lead ions from synthetic semiconductor industrial wastewater by palm shell activated carbon. Int. J. Environ. Sci. Tech., 7 (4), 751-758 (8 pages).

Pagnanelli, F.; Esposito, L.; Veglio, F., (2003). Metal speciation and $\mathrm{pH}$ effect on $\mathrm{Pb}, \mathrm{Cu}, \mathrm{Zn}$ and $\mathrm{Cd}$ biosorption onto Sphaerotilus natans: Langmuir-type empirical model. Water Res., 37 (3), 627-633 (7 pages).

Pan, S.; Lin, C.; Tseng, D., (2003). Reusing sewage sludge ash as adsorbent for copper removal from wastewater. Res. Conserv. Recycl., 39 (1), 79-90 (12 pages).

Pehlivan, E.; Arslan, G., (2007). Removal of metal ions using lignite in aqueous solution-Low cost biosorbents. Fuel Process Tech., 88 (1), 99-106 (8 pages).

Prasad, K.; Gopikrishna, P.; Kala, R.; Rao, T. P.; Naidu, G. R. K., (2006). Solid phase extraction vis-`a-vis coprecipitation preconcentration of cadmium and lead from soils onto 5,7dibromoquinoline-8-ol embedded benzophenone and determination by FAAS. Talanta, 69 (4), 938-945 (8 pages).

Qi, B. C.; Aldrich, C., (2008). Biosorption of heavy metals from aqueous solutions with tobacco dust. Biores. Tech., 99 (13), 5595-5601 (7 pages).

Radhika, V.; Subramanian, S.; Natarajan, K. A., (2006). Bioremediation of zinc using Desulfotomaculum nigrificans: Bioprecipitation and characterization studies. Water Res., 40 (19), 3628- 3636 (9 pages).

Saeed, A.; Iqbala, M.; Akhtar, M. W., (2005). Removal and recovery of lead(II) from single and multimetal $(\mathrm{Cd}, \mathrm{Cu}, \mathrm{Ni}$, $\mathrm{Zn}$ ) solutions by crop milling waste (black gram husk). J. Hazard. Mater., 117 (1), 65-73 (9 pages).

Shah, B. A.; Shah, A. V.; Singh, R. R., (2009). Sorption isotherms and kinetics of chromium uptake from wastewater using natural sorbent material. Int. J. Environ. Sci. Tech., 6 (1), 77-90 (14 pages).

Volesky, Z. R.; Holan, A., (1995). Biosorption of heavy metals. Biotech. Prog., 11, 235-250 (16 pages).

Weng, C. H.; Huang, C. P., (2004). Adsorption characteristics of $\mathrm{Zn}(\mathrm{II})$ from dilute aqueous solution by fly ash. Colloid. Surf. A., 247 (1-3), 137-143 (7 pages).

Yu, B.; Zhang, Y.; Shukla, A.; Shukla, S. S.; Dorris, K. L., (2001). The removal of heavy metals from aqueous solutions by sawdust adsorption - removal of lead and comparison of its adsorption with copper. J. Hazard. Mater., 84 (1), 83-94 (12 pages).

Zvinowanda, C. M.; Okonkwo, J. O.; Shabalala, P. N.; Agyei, N. M., (2009). A novel adsorbent for heavy metal remediation in aqueous environments. Int. J. Environ. Sci. Tech., 6 (3), 425434 (10 pages).

Zulkali, M. M. D.; Ahmad, A. L.; Norulakmal, N. H., (2006). Oryza sativa L. husk as heavy metal adsorbent: Optimization with lead as model solution. Biores. Tech., 97 (1), 21-25 (5 pages).

\section{AUTHOR (S) BIOSKETCHES}

Zavvar Mousavi, H., Ph.D. Associate professor, Department of Chemistry, College of Science, Semnan University, Semnan, Iran. Email: hzmousavi@semnan.ac.ir

Seyedi, S. R., M. Sc. Department of Chemistry, College of Science, Semnan University, Semnan, Iran. Email: rezvaneh.seyedi@yahoo.com

How to cite this article: (Harvard style)

Zavvar Mousavi, H.; Seyedi, S. R., (2011). Nettle ash as a low cost adsorbent for the removal of Nickel and Cadmium from wastewater. Int. J. Environ. Sci. Tech., 8 (1), 195-202. 